\title{
Soluble guanylate cyclase stimulation: an emerging option in pulmonary hypertension therapy
}

\author{
H.A. Ghofrani and F. Grimminger
}

ABSTRACT: The prognosis for patients with pulmonary hypertension remains poor despite recent treatment advances, and there is a need for therapies with new modes of action. Nitric oxide (NO) is an endogenous vasodilator, the levels of which are regulated throughout the lung to ensure preferential perfusion of well-ventilated regions. Drugs that act in synergy with endogenous NO would therefore promote pulmonary vasodilation while maintaining optimal gas exchange.

Riociguat is an oral stimulator of the NO receptor soluble guanylate cyclase. It synergises with NO and has demonstrated vasodilatory and antiremodelling properties in preclinical studies. Riociguat has been shown to have a favourable safety profile in healthy volunteers and in patients with pulmonary hypertension. Pharmacokinetic analyses have revealed substantial interindividual variation, suggesting that individual dose titration will be required.

In a proof-of-concept study of patients with pulmonary arterial hypertension or chronic thromboembolic pulmonary hypertension, riociguat improved cardiopulmonary haemodynamics from baseline. It also caused systemic vasodilation, which was well tolerated but should be monitored in future studies. Dose titration of riociguat should promote pulmonary vasodilation while maintaining control of systemic effects, and has been investigated in a phase-Il study of patients with pulmonary arterial hypertension or chronic thromboembolic pulmonary hypertension. Preliminary results indicate that phase-III trials are warranted.

\section{KEYWORDS: Haemodynamics, pulmonary hypertension, riociguat}

E ndothelial cell-derived nitric oxide (NO) acts on vascular smooth muscle cells in healthy subjects to induce vasodilation by increasing production of the secondary messenger cyclic guanosine monophosphate (cGMP) via the activation of soluble guanylate cyclase (sGC) $[1,2]$. Expression of the enzyme responsible for the production of endothelial cell-derived $\mathrm{NO}$, endothelial NO synthase, is reduced in the lungs of patients with pulmonary arterial hypertension (PAH) compared with those of controls [3, 4].

In the healthy lung, NO plays a key role in the maintenance of ventilation/perfusion $\left(V^{\prime} / Q^{\prime}\right)$ matching. Levels of $\mathrm{NO}$ are low in regions of low ventilation (resulting in vasoconstriction) and high in regions of high ventilation (resulting in vasodilation), causing blood flow to be directed preferentially towards well-ventilated regions of the lung, ensuring efficient oxygenation (fig. 1). Drugs that synergise with NO will, therefore, cause vasodilation preferentially in well-ventilated regions of the lung, maintaining $V^{\prime} / Q^{\prime}$ matching. By contrast, nonselective vasodilators, such as intravenous prostacyclin analogues and oral endothelin receptor antagonists, can worsen $V^{\prime} / Q^{\prime}$ mismatch and hypoxaemia under certain circumstances, for example in pulmonary hypertension associated with lung disease [5-7].

Therefore, there are strong grounds for the development of pharmacotherapies targeting the NO signalling pathway in pulmonary hypertension. Inhaled NO is a useful short-term vasodilator screening agent for the identification of those patients with pulmonary arterial hypertension (PAH) who will respond to treatment with calcium channel blockers [8-10]. However, inhaled NO and nitrates are unsuitable as long-term treatments for pulmonary hypertension, owing to the significant numbers of nonresponding patients [11, 12], the development of tolerance [13] and/or the serious problem of rebound pulmonary hypertension following discontinuation of treatment [14, 15]. Targeting of a downstream component of the NO signalling pathway has met with more success; sildenafil prevents the degradation of cGMP by inhibiting phosphodiesterase (PDE)5, and has
AFFILIATIONS

Dept of Internal Medicine, Medical Clinic IIN, University Hospital Giessen and Marburg, Giessen, Germany.

\section{CORRESPONDENCE}

H.A. Ghofrani

Dept of Internal Medicine Medical Clinic IIN, University Hospital Giessen and Marburg GmbH, Klinikstrasse 36, 35392 Giessen, Germany. Fax: 496419942419 E-mail: ardeschir.ghofrani@ innere.med.uni-giessen.de

Received:

December 082008

Accepted after revision December 172008

STATEMENT OF INTEREST

H.A. Ghofrani has received research grants from Bayer Schering, Pfizer, Ergonex and Encysive. H.A. Ghofrani has received honoraria payments from Bayer Schering, Pfizer, Actelion, Encysive and GlaxoSmithKline. His travel to the ERS Congress was funded by GlaxoSmithKline. H.A. Ghofrani has received fees for consultancy and/or has advisory board relationships with Bayer Schering, Pfizer Actelion, Encysive, Ergonex and GlaxoSmithKline. F. Grimminger has received research grants from Bayer Schering, Pfizer, Ergonex and Encysive. F. Grimminger has received honoraria payments from Bayer Schering, Pfizer. Actelion, Encysive and Novartis Pharmaceuticals UK Limited. F. Grimminger has received fees for consultancy and/or has an advisory board relationship with Nycomed (Altana Pharma).

\section{PROVENANCE}

Publication of this peer-reviewed article was made possible by funding from Bayer Schering Pharma AG, Germany (principal Sponsor, European Respiratory Review issue 111).

European Respiratory Review Print ISSN 0905-9180 Online ISSN 1600-0617 
a) Matching

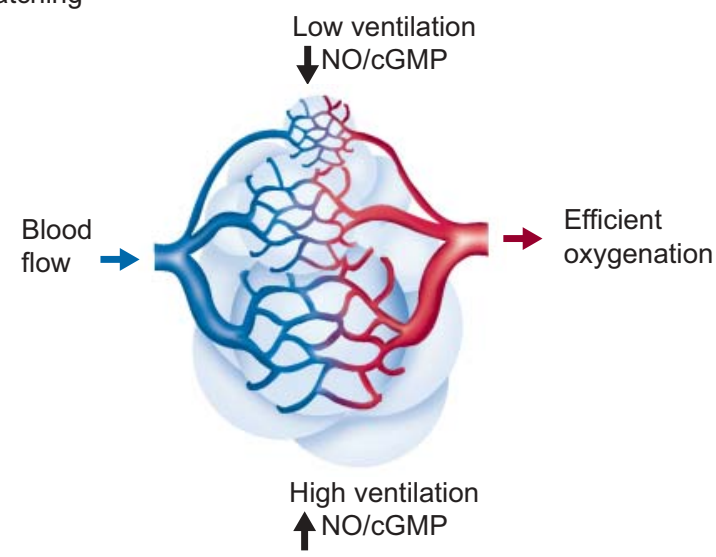

b) Mismatching

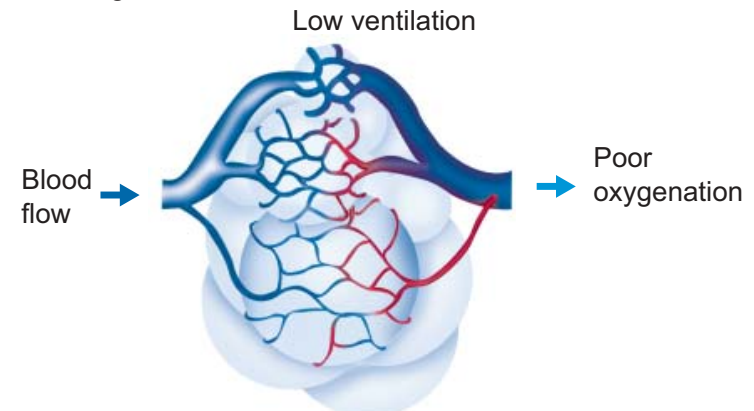

High ventilation

FIGURE 1. The role of nitric oxide (NO) in ventilation/perfusion matching in the lung. cGMP: cyclic guanosine monophosphate.

been approved for the treatment of PAH [16-18]. However, the activity of sildenafil depends on the presence of an intact NOsGC-cGMP axis, and its efficacy may be limited in the presence of low NO levels [16, 19].

In general, survival rates of patients with PAH have improved coincidentally with the introduction of a range of specific therapies, but prognosis still remains poor [20], indicating that new approaches are still needed. Investigation of alternative targets within the NO signalling pathway has centred on the direct stimulation of sGC, leading to a new class of potential agents for pulmonary hypertension treatment: direct sGC stimulators that are not limited by low endogenous NO levels. Riociguat (BAY 63-2521) is the first of these drugs to enter clinical study.

\section{DIRECT STIMULATION OF SGC}

sGC is a heterodimer of a larger $\alpha$-subunit and a smaller haembinding $\beta$-subunit [21]. The binding of NO to sGC causes the activation of sGC and synthesis of the second messenger cGMP [22]. In turn, cGMP binds to and activates cGMP-dependent protein kinase (protein kinase G) to regulate cytosolic calcium ion concentration, which desensitises actin-myosin contractility and induces vasodilation [23, 24].

Increased sGC expression occurs in experimental hypoxiainduced pulmonary hypertension [25, 26]. Upregulation of
sGC was similarly detected in the structurally remodelled smooth muscle layer in chronic hypoxic mouse lungs and lungs from rats with monocrotaline (MCT)-induced pulmonary hypertension [27]. Furthermore, analysis of lung biopsy tissue samples from patients with idiopathic $\mathrm{PAH}$ revealed a strong up-regulation of sGC in pulmonary arterial vessels compared with samples from healthy subjects [27].

YC-1, a synthetic benzylindazole derivative, was first described in 1978 [28] and characterised as an NO-independent, haemdependent sGC stimulator almost two decades later [29]. As well as increasing sGC activity in the absence of NO, YC-1 acted in synergy with NO to stimulate sGC [30-32], yet it proved to be a relatively weak vasodilator and inhibited PDEs [33]; therefore, the search began for a new generation of indazoles that were more potent and more specific with respect to sGC. This resulted in the identification of BAY 41-2272 and BAY 41-8543 [34-36], two predecessors of riociguat that proved to be more potent direct stimulators of SGC than YC-1 in vitro and ex vivo, and produced no clinically relevant PDE inhibition (this has been previously reviewed elsewhere [37]).

BAY 41-2272 was investigated in numerous preclinical studies, and was shown to be effective in treating various animal models of pulmonary hypertension, as well as inhibiting cardiovascular remodelling [38-41]. BAY 41-8543 caused pulmonary vasodilation and improved systemic arterial oxygenation in a sheep model of pulmonary hypertension [42]. Although the preclinical data showed promise, further pharmacokinetic optimisation was required to yield a compound suitable for clinical development.

The optimised sGC stimulator riociguat was identified following pharmacological and pharmacokinetic profiling of around 1,000 additional compounds [37]. Its mode of action is shown in figure 2 [43]. Riociguat $(0.1-100 \mu \mathrm{M})$ dose-dependently stimulated sGC activity up to 73-fold in vitro and synergised with the NO donor complex diethylamine/NO $(0.1 \mu \mathrm{M})$ to increase sGC activity up to 112-fold [27]. Riociguat was found to activate sGC by an NO-independent but haem-dependent mechanism, and it had no effect on a broad range of cyclic nucleotide metabolising enzymes, including PDEs [27].

Riociguat effectively reduced pulmonary hypertension and reversed the associated right heart hypertrophy and vascular remodelling in mouse and rat models of the disease (hypoxiaand MCT-induced pulmonary hypertension, respectively), compared with untreated controls [27]. Figure 3 exemplifies the effects of riociguat on right heart hypertrophy and degree of muscularisation of small pulmonary arteries in MCT-treated rats.

\section{RIOCIGUAT IN HEALTHY SUBJECTS: PHASE-I STUDY}

The safety profile, pharmacokinetics and pharmacodynamics of single oral doses of riociguat $(0.25-5 \mathrm{mg}$ as a solution and a $2.5 \mathrm{mg}$ immediate-release tablet formulation) were determined under fasting conditions in 58 healthy male subjects in a singlecentre, randomised, placebo-controlled, single-blinded, parallel-group phase-I study [44]. Study cohorts received increasing doses of riociguat stepwise, dependent on safety evaluation of the preceding dose.

The plasma concentration-time profiles for riociguat are shown in figure 4 . Riociguat was rapidly absorbed, with a 


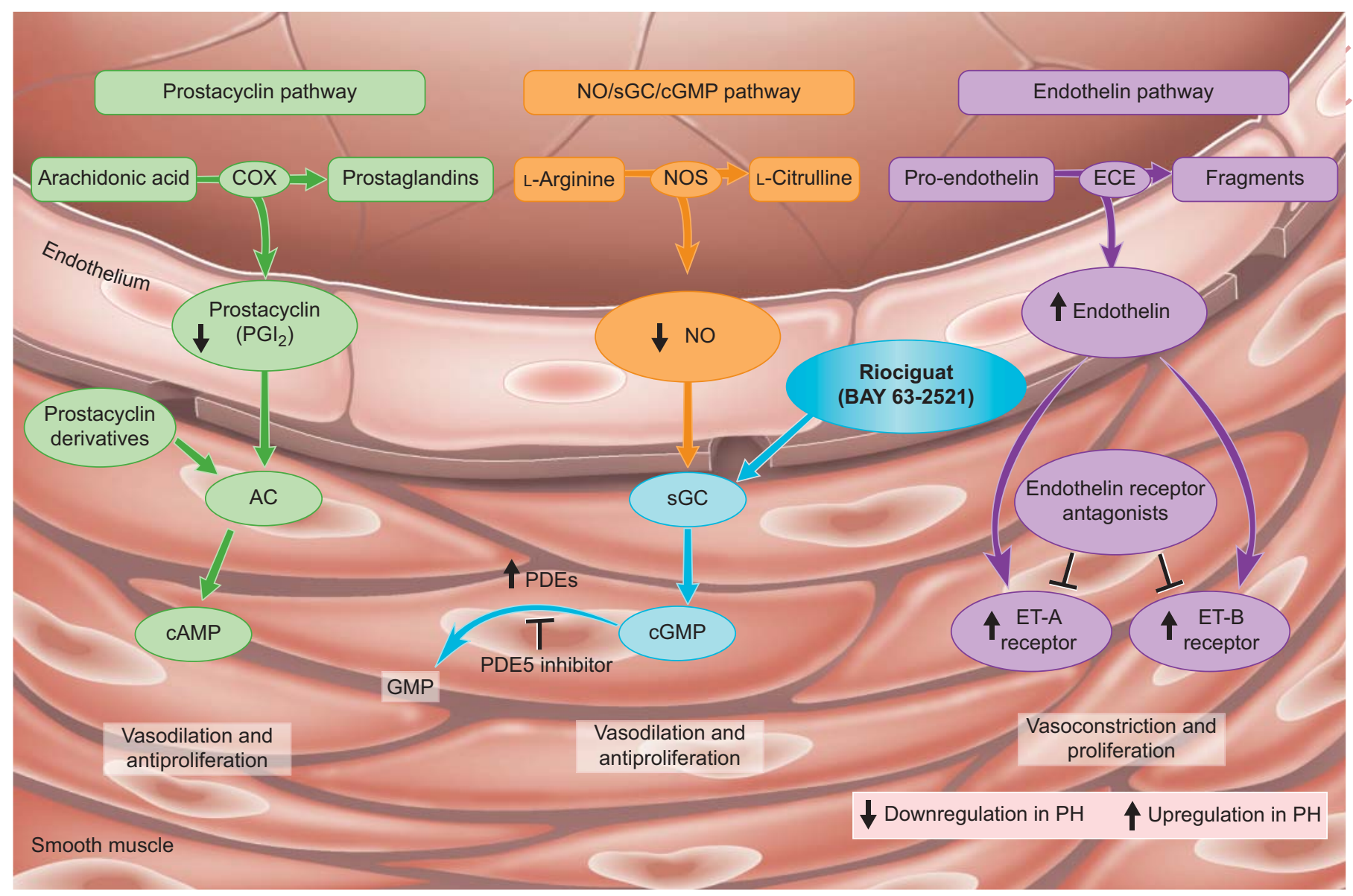

FIGURE 2. Mode of action of riociguat. Riociguat acts directly on the nitric oxide (NO) receptor soluble guanylate cyclase (sGC), and is able to stimulate the enzyme independently and in synergy with NO. AC: adenylate cyclase; cAMP: cyclic adenosine monophosphate; cGMP: cyclic guanosine monophosphate; COX: cyclo-oxygenase: ECE: endothelin converting enzyme; ET: endothelin; GMP: guanosine monophosphate; NOS: NO synthase; PDE: phosphodiesterase; PH: pulmonary hypertension. Reproduced from [43] with permission from the publisher.

mean time from administration to maximum plasma concentration of $0.5-1.5 \mathrm{~h}$. Mean maximum plasma concentration and mean area under the plasma concentration-time curve for riociguat were approximately linearly related to dose. Mean elimination half-life was 5-9 h. Bioavailability of the tablet formulation was similar to that of the oral solution. There was a high degree of interindividual variation in plasma riociguat concentrations, which will necessitate individual titration in the clinical situation.

Riociguat was well tolerated up to $2.5 \mathrm{mg}$, with the $5 \mathrm{mg}$ dose being less well tolerated and associated with more adverse events including headache, nasal congestion, flushing, feeling hot, orthostatic hypotension and palpitation. Heart rate increased in proportion to dose over the range of 1 to $5 \mathrm{mg}$. Heart rate is considered a very sensitive noninvasive parameter for indirect estimation of the effect of a vasodilating agent on the cardiovascular system in healthy young subjects, with changes in heart rate compensating for changes in blood pressure. There was a slight decrease in diastolic blood pressure but no significant decrease in systolic blood pressure. With respect to vasoactive hormones, plasma norepinephrine increased significantly with the $5 \mathrm{mg}$ dose, renin with $1-5 \mathrm{mg}$ doses, and cGMP with $2.5 \mathrm{mg}$ and $5 \mathrm{mg}$ doses.

\section{RIOCIGUAT IN PULMONARY HYPERTENSION: PROOF- OF-CONCEPT STUDY}

A two-part proof-of-concept study of riociguat was undertaken at a single German clinical centre to determine the safety, tolerability, pharmacodynamics and pharmacokinetics of riociguat administered as an oral solution in patients with pulmonary hypertension $[45,46]$. The study population included male and female patients aged $18-80$ yrs with mean pulmonary vascular resistance (PVR) $>300 \mathrm{dyn} \cdot \mathrm{s} \cdot \mathrm{cm}^{-5}$, and a diagnosis of PAH, pulmonary hypertension associated with mild-to-moderate interstitial lung disease, or chronic thromboembolic pulmonary hypertension (CTEPH), corresponding to Venice protocol groups 1, 3 and 4, respectively [47].

Haemodynamic parameters and gas exchange variables were first measured before, during and after NO inhalation (10$20 \mathrm{ppm} \mathrm{NO}$ for $10 \mathrm{~min}$ ), and riociguat was administered after haemodynamic parameters had returned to baseline values. In the initial part of the study, the optimal tolerated dose of riociguat 

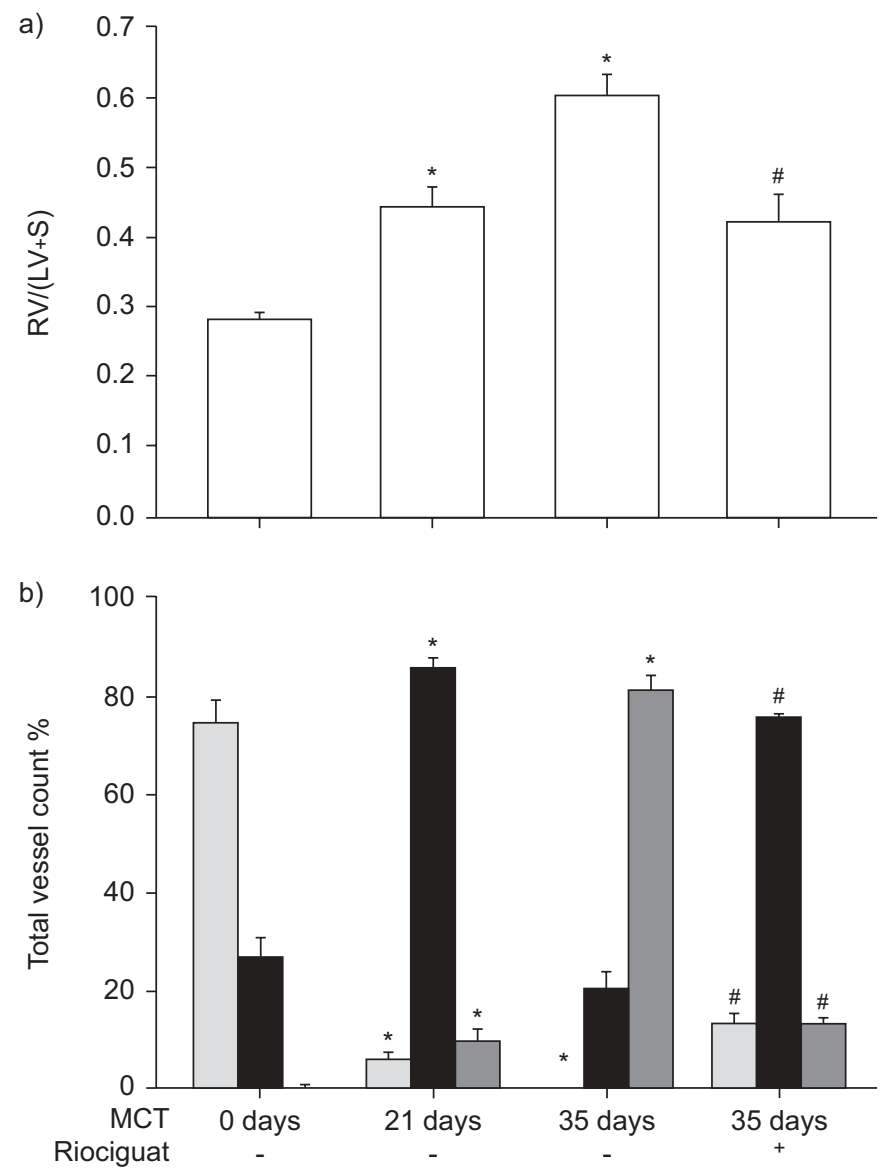

FIGURE 3. Effect of riociguat on a) right heart hypertrophy (assessed by the ratio of right ventricle weight to left ventricle and septum weight $(R V /(L V+S))$ and b) degree of muscularisation of small pulmonary arteries in rats with monocrotaline (MCT)-induced pulmonary hypertension. Rats received MCT or saline by subcutaneous injection and were investigated on day 21 or 35 . Oral riociguat $\left(10 \mathrm{mg} \cdot \mathrm{kg}^{-1}\right)$ was administered from day 21 to 35 in MCT-treated animals $(n=8)$, Degree of muscularisation is given as percentage of non- $(\square)$, partially- $(\mathbf{\square})$ or fully(回) muscularised pulmonary arteries from total vessel count (vessels sized 20$70 \mu \mathrm{m})$ in MCT-treated animals. *: $p<0.05$ versus control; ${ }^{*}: \mathrm{p}<0.05$ versus MCT at day 35. Modified and reproduced from [27] with permission from the publisher.

was identified by incrementally increasing the dose at hourly intervals in four patients: $0.5+1+1=2.5 \mathrm{mg} \quad(\mathrm{n}=2)$ and $1+2+2=5 \mathrm{mg}(\mathrm{n}=2)$. The $5 \mathrm{mg}$ total dose caused asymptomatic hypotension in one patient, so doses of $1 \mathrm{mg}$ and $2.5 \mathrm{mg}$ were chosen for the second part of the study. Riociguat $1 \mathrm{mg}(\mathrm{n}=5)$ and $2.5 \mathrm{mg}(\mathrm{n}=10)$ doses were administered in the second part of the study and measurements were compared with peak intervention values for inhaled $\mathrm{NO}$ and post-NO intervention baseline values.

Riociguat was well tolerated in this proof-of-concept study. Three patients experienced mild, possibly treatment-related adverse events (dizziness, nasal congestion and hot flush). There were no clinically meaningful effects on vital signs, ECGs or routine laboratory test values. Neither dose produced deterioration in gas exchange or $V^{\prime} / Q^{\prime}$ matching despite strong pulmonary vasodilation.

Riociguat doses of $1 \mathrm{mg}$ or $2.5 \mathrm{mg}$ produced clinically and statistically significant improvements in PVR, mean pulmonary

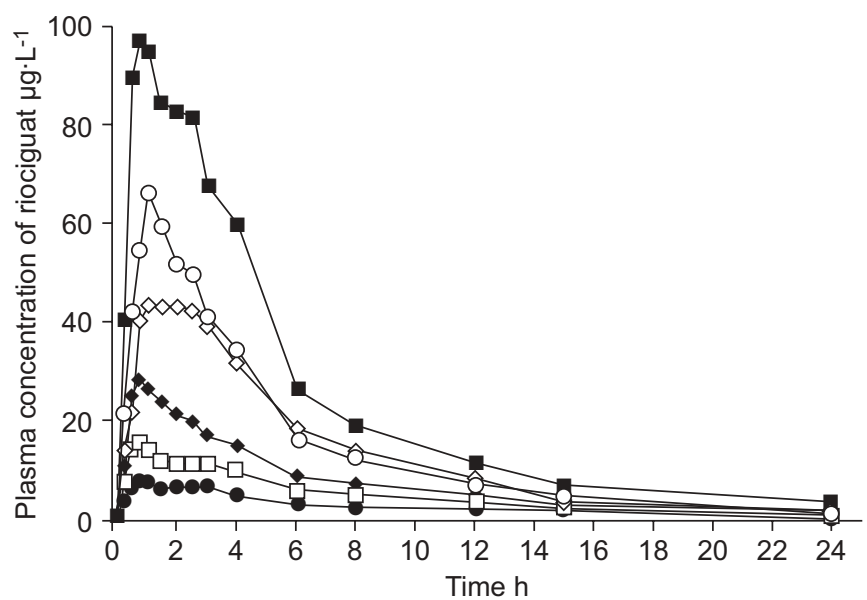

FIGURE 4. Plasma concentrations of riociguat after oral administration to healthy subjects. $\bullet 0.25 \mathrm{mg}$ solution $(\mathrm{n}=6) ; \square: 0.5 \mathrm{mg}$ solution $(\mathrm{n}=5) ; \diamond: 1.0 \mathrm{mg}$ solution ( $n=12) ; 0: 2.5 \mathrm{mg}$ solution $(n=6) ; \mathbf{\square}: 5.0 \mathrm{mg}$ solution $(n=10) ; \diamond: 2.5 \mathrm{mg}$ tablet $(n=6)$. Modified and reproduced from [44] permission from the publisher.

arterial pressure $(\mathrm{Ppa})$ and cardiac index $(\mathrm{CI})$ in a concentrationdependent manner. A subanalysis of patients with CTEPH and patients with $\mathrm{PAH}$ revealed significant increases in $\mathrm{CI}$ in both patient groups (fig. 5). Riociguat-induced changes in haemodynamic parameters were also clinically and statistically significant compared with those induced by inhaled NO.

Riociguat caused systemic vasodilation as well as pulmonary vasodilation, significantly reducing systolic blood pressure and systemic vascular resistance. Although mean systolic blood pressure remained $>110 \mathrm{mmHg}$ in this small proof-ofconcept study, these results again suggest that individual dose titration will be required in order to control systemic effects.

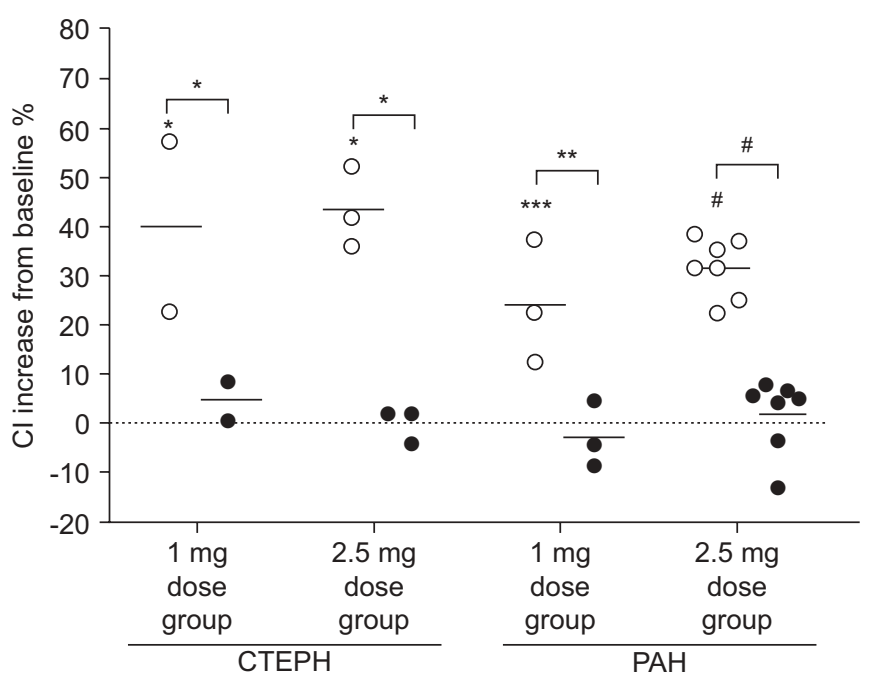

FIGURE 5. Cardiac index $(\mathrm{Cl})$ changes from baseline following single oral doses of riociguat $(\bigcirc) 1 \mathrm{mg}$ and $2.5 \mathrm{mg}$ compared with inhaled nitric oxide $(\bullet)$ in patients with pulmonary hypertension. Horizontal lines indicate point estimates (least-squares means) in each case. CTEPH: chronic thromboembolic pulmonary hypertension; $\mathrm{PAH}$ : pulmonary arterial hypertension. Statistical significance was measured by the F statistic. ${ }^{*}: p<0.05 ;{ }^{* *}: p<0.01 ;{ }^{* *}: p<0.001 ;{ }^{*}: p<0.0001$. Reproduced from [45] with permission from the publisher. 
The pharmacokinetic properties of riociguat were determined in patients with pulmonary hypertension in the second part of the proof-of-concept study [45, 46]. Riociguat was rapidly absorbed and there was a high degree of interindividual variation in plasma riociguat concentrations, consistent with pharmacokinetic data from the phase-I study [44].

\section{RIOCIGUAT IN PAH AND CTEPH: PHASE-II STUDY}

On the basis of the promising results shown in the proof-ofconcept study, an open-label uncontrolled phase-II trial of riociguat administered by dose titration has been initiated at 15 German clinical centres.

As the proof-of-concept study showed promising results in a small number of patients with CTEPH, it was decided to investigate this population further as part of the phase-II study. There is a clear unmet need for pharmacotherapy in patients with CTEPH, notably those with inoperable CTEPH or persistent post-pulmonary endarterectomy pulmonary hypertension (a review of treatment options for patients with CTEPH can be found in the article by LANG [48] in the present issue of the European Respiratory Review).

The aim of the phase-II trial is to investigate the safety profile, tolerability, pharmacodynamics and therapeutic potential of oral riociguat in dose titration over a period of 12 weeks in patients with PAH or CTEPH (PAH therapy-naïve or undergoing treatment with oral bosentan). The trial has progressed following interim analyses that yielded promising results, and it is anticipated that the final results will be sufficiently encouraging to warrant the initiation of randomised, controlled, phase-III clinical studies of riociguat.

\section{CONCLUSIONS}

Riociguat, a direct sGC stimulator, offers the potential for a new mode of action for pulmonary hypertension treatment. Preclinical studies have shown that it stimulates sGC directly, increasing the activity of sGC independently of $\mathrm{NO}$ and increasing sensitivity to low levels of endogenous NO. In animal models of pulmonary hypertension, riociguat reduced $P$ pa and markedly attenuated cardiac hypertrophy and vascular remodelling.

Phase-I and proof-of-concept studies in healthy subjects and patients with pulmonary hypertension have indicated that riociguat has a favourable safety profile and is well tolerated. These studies have also established the probable therapeutic dose range of riociguat on the basis of its acute haemodynamic effects in patients with moderate-to-severe pulmonary hypertension. Both studies showed systemic effects and interindividual variation, which should be addressed successfully by titration of riociguat dose on a case-by-case basis.

A multicentre phase-II trial of riociguat has been initiated in order to determine the safety profile, tolerability, pharmacodynamics and therapeutic potential of riociguat in patients with pulmonary arterial hypertension or chronic thromboembolic pulmonary hypertension when oral doses are individually titrated according to target systolic blood pressure. The results of this uncontrolled open-label trial will require verification in a randomised, controlled phase-III study. In planned phase-III trials, riociguat will be investigated in the first-line setting in patients with chronic thromboembolic pulmonary hypertension, for whom no medical therapy has yet been approved. The safety and efficacy of riociguat as a monotherapy and in combination with established treatments will also be determined in patients with pulmonary arterial hypertension.

\section{ACKNOWLEDGEMENTS}

The author would like to thank C. Mulligan of Oxford PharmaGenesis who provided medical writing assistance funded by Bayer HealthCare AG.

\section{REFERENCES}

1 Ignarro LJ, Buga GM, Wood KS, Byrns RE, Chaudhuri G. Endothelium-derived relaxing factor produced and released from artery and vein is nitric oxide. Proc Natl Acad Sci USA 1987; 84: 9265-9269.

2 Arnold WP, Mittal CK, Katsuki S, Murad F. Nitric oxide activates guanylate cyclase and increases guanosine $3^{\prime}: 5^{\prime}-$ cyclic monophosphate levels in various tissue preparations. Proc Natl Acad Sci USA 1977; 74: 3203-3207.

3 Giaid A, Saleh D. Reduced expression of endothelial nitric oxide synthase in the lungs of patients with pulmonary hypertension. N Engl J Med 1995; 333: 214-221.

4 Humbert M, Sitbon O, Simonneau G. Treatment of pulmonary arterial hypertension. N Engl J Med 2004; 351: 1425-1436.

5 Archer SL, Mike D, Crow J, Long W, Weir EK. A placebocontrolled trial of prostacyclin in acute respiratory failure in COPD. Chest 1996; 109: 750-755.

6 Radermacher P, Santak B, Wust HJ, Tarnow J, Falke KJ. Prostacyclin and right ventricular function in patients with pulmonary hypertension associated with ARDS. Intensive Care Med 1990; 16: 227-232.

7 Stolz D, Rasch H, Linka A, et al. A randomized, controlled trial of bosentan in severe COPD. Eur Respir J 2008; 32: 619-628.

8 Sitbon O, Brenot F, Denjean A, et al. Inhaled nitric oxide as a screening vasodilator agent in primary pulmonary hypertension. A dose-response study and comparison with prostacyclin. Am J Respir Crit Care Med 1995; 151: 384-389.

9 Sitbon O, Humbert M, Jagot JL, et al. Inhaled nitric oxide as a screening agent for safely identifying responders to oral calcium-channel blockers in primary pulmonary hypertension. Eur Respir J 1998; 12: 265-270.

10 Sitbon O, Humbert M, Jais X, et al. Long-term response to calcium channel blockers in idiopathic pulmonary arterial hypertension. Circulation 2005; 111: 3105-3111.

11 Klinger JR, Thaker S, Houtchens J, Preston IR, Hill NS, Farber HW. Pulmonary hemodynamic responses to brain natriuretic peptide and sildenafil in patients with pulmonary arterial hypertension. Chest 2006; 129: 417-425.

12 Krasuski RA, Warner JJ, Wang A, Harrison JK, Tapson VF, Bashore TM. Inhaled nitric oxide selectively dilates pulmonary vasculature in adult patients with pulmonary hypertension, irrespective of etiology. J Am Coll Cardiol 2000; 36: 2204-2211.

13 Munzel T, Daiber A, Mulsch A. Explaining the phenomenon of nitrate tolerance. Circ Res 2005; 97: 618-628. 
14 Atz AM, Adatia I, Wessel DL. Rebound pulmonary hypertension after inhalation of nitric oxide. Ann Thorac Surg 1996; 62: 1759-1764.

15 Ichinose F, Roberts JD Jr, Zapol WM. Inhaled nitric oxide: a selective pulmonary vasodilator: current uses and therapeutic potential. Circulation 2004; 109: 3106-3111.

16 Galie N, Ghofrani HA, Torbicki A, et al. Sildenafil citrate therapy for pulmonary arterial hypertension. $N$ Engl J Med 2005; 353: 2148-2157.

17 Ghofrani HA, Wiedemann R, Rose F, et al. Sildenafil for treatment of lung fibrosis and pulmonary hypertension: a randomised controlled trial. Lancet 2002; 360: 895-900.

18 Wilkins MR, Wharton J, Grimminger F, Ghofrani HA. Phosphodiesterase inhibitors for the treatment of pulmonary hypertension. Eur Respir J 2008; 32: 198-209.

19 Michelakis ED. The role of the NO axis and its therapeutic implications in pulmonary arterial hypertension. Heart Fail Rev 2003; 8: 5-21.

20 Naeije R, Huez S. Expert opinion on available options treating pulmonary arterial hypertension. Expert Opin Pharmacother 2007; 8: 2247-2265.

21 Kamisaki Y, Saheki S, Nakane M, et al. Soluble guanylate cyclase from rat lung exists as a heterodimer. J Biol Chem 1986; 261: 7236-7241.

22 Rapoport RM, Murad F. Endothelium-dependent and nitrovasodilator-induced relaxation of vascular smooth muscle: role of cyclic GMP, 1983; 9: 281-296.

23 Munzel T, Feil R, Mulsch A, Lohmann SM, Hofmann F, Walter U. Physiology and pathophysiology of vascular signaling controlled by guanosine $3^{\prime}, 5^{\prime}$-cyclic monophosphatedependent protein kinase. Circulation 2003; 108: 2172-2183.

24 Warner TD, Mitchell JA, Sheng H, Murad F. Effects of cyclic GMP on smooth muscle relaxation. Adv Pharmacol 1994; 26: 171-194.

25 Li D, Laubach VE, Johns RA. Upregulation of lung soluble guanylate cyclase during chronic hypoxia is prevented by deletion of eNOS. Am J Physiol Lung Cell Mol Physiol 2001; 281: L369-L376.

26 Li D, Zhou N, Johns RA. Soluble guanylate cyclase gene expression and localization in rat lung after exposure to hypoxia. Am J Physiol 1999; 277: L841-L847.

27 Schermuly R, Stasch JP, Pullamsetti SS, et al. Expression and function of soluble guanylate cyclase in pulmonary arterial hypertension. Eur Respir J 2008; 32: 881-891.

28 Yoshina S, Tanaka A, Kuo SC. [Studies on heterocyclic compounds. XXXIV. Synthesis of furo[3,2-c]pyrazole derivatives. 2) Electrophilic substitution of 1,3-diphenylfuro[3,2c]pyrazole]. Yakugaku Zasshi 1978; 98: 204-209.

29 Ko FN, Wu CC, Kuo SC, Lee FY, Teng CM. YC-1, a novel activator of platelet guanylate cyclase. Blood 1994; 84: 4226-4233.

30 Hoenicka M, Becker EM, Apeler H, et al. Purified soluble guanylyl cyclase expressed in a baculovirus/Sf9 system: stimulation by YC-1, nitric oxide, and carbon monoxide. J Mol Med 1999; 77: 14-23.

31 Mulsch A, Bauersachs J, Schafer A, Stasch JP, Kast R, Busse R. Effect of YC-1, an NO-independent, superoxidesensitive stimulator of soluble guanylyl cyclase, on smooth muscle responsiveness to nitrovasodilators. $\mathrm{Br}$ J Pharmacol 1997; 120: 681-689.
32 Schmidt K, Schrammel A, Koesling D, Mayer B. Molecular mechanisms involved in the synergistic activation of soluble guanylyl cyclase by YC-1 and nitric oxide in endothelial cells. Mol Pharmacol 2001; 59: 220-224.

33 Galle J, Zabel U, Hubner U, et al. Effects of the soluble guanylyl cyclase activator, YC-1, on vascular tone, cyclic GMP levels and phosphodiesterase activity. Br J Pharmacol 1999; 127: 195-203.

34 Stasch JP, Alonso-Alija C, Apeler H, et al. Pharmacological actions of a novel NO-independent guanylyl cyclase stimulator, BAY 41-8543: in vitro studies. Br J Pharmacol 2002; 135: 333-343.

35 Stasch JP, Becker EM, Alonso-Alija C, et al. NO-independent regulatory site on soluble guanylate cyclase. Nature 2001; 410: 212-215.

36 Straub A, Stasch JP, Alonso-Alija C, et al. NO-independent stimulators of soluble guanylate cyclase. Bioorg Med Chem Lett 2001; 11: 781-784.

37 Evgenov OV, Pacher P, Schmidt PM, Hasko G, Schmidt HH, Stasch JP. NO-independent stimulators and activators of soluble guanylate cyclase: discovery and therapeutic potential. Nat Rev Drug Discov 2006; 5: 755-768.

38 Deruelle P, Balasubramaniam V, Kunig AM, Seedorf GJ, Markham NE, Abman SH. BAY 41-2272, a direct activator of soluble guanylate cyclase, reduces right ventricular hypertrophy and prevents pulmonary vascular remodeling during chronic hypoxia in neonatal rats. Biol Neonate 2006; 90: 135-144.

39 Deruelle P, Grover TR, Abman SH. Pulmonary vascular effects of nitric oxide-cGMP augmentation in a model of chronic pulmonary hypertension in fetal and neonatal sheep. Am J Physiol Lung Cell Mol Physiol 2005; 289: L798-L806.

40 Dumitrascu R, Weissmann N, Ghofrani HA, et al. Activation of soluble guanylate cyclase reverses experimental pulmonary hypertension and vascular remodeling. Circulation 2006; 113: 286-295.

41 Evgenov OV, Ichinose F, Evgenov NV, et al. Soluble guanylate cyclase activator reverses acute pulmonary hypertension and augments the pulmonary vasodilator response to inhaled nitric oxide in awake lambs. Circulation 2004; 110: 2253-2259.

42 Evgenov OV, Kohane DS, Bloch KD, et al. Inhaled agonists of soluble guanylate cyclase induce selective pulmonary vasodilation. Am J Respir Crit Care Med 2007; 176: 1-8.

43 Ghofrani HA, Grimminger F. Modulating cGMP to treat lung diseases. Handb Exp Pharmacol 2009; 191: 469-483.

44 Frey R, Mück W, Unger S, Artmeier-Brandt U, Weimann G, Wensing G. Single-dose pharmacokinetics, tolerability and safety of the soluble guanylate cyclase stimulator BAY 632521; an ascending-dose study in healthy male volunteers. J Clin Pharmacol 2008; 48: 926-934.

45 Grimminger F, Weimann G, Frey R, et al. First acute haemodynamic study of soluble guanylate cyclase stimulator riociguat in pulmonary hypertension. Eur Respir J 2009; [Epub ahead of print PMID: 19129292].

46 Ghofrani HA, Weimann G, Frey R, et al. BAY 63-2521, an oral soluble guanylate cyclase stimulator, has a favourable safety profile, improves cardiopulmonary haemodynamics and has therapeutic potential in pulmonary hypertension. BMC Pharmacology 2007; 7: S8. 
47 Simonneau G, Galie N, Rubin LJ, et al. Clinical classification of pulmonary hypertension. J Am Coll Cardiol 2004; 43: Suppl. 12, 5S-12S.
48 Lang IM. Managing chronic thromboembolic pulmonary hypertension: pharmacological treatment options. Eur Respir Rev 2009; 18: 24-28. 